\title{
RESEARCH
}

Open Access

\section{The validity and reliability of Persian version of smartphone addiction questionnaire in Iran}

\author{
Zahra Shaahmadi ${ }^{1}$, Touraj Ahmadi Jouybari ${ }^{1}$, Bahare Lotfi ${ }^{1}$, Abbas Aghae ${ }^{2 *}$ (D) and Reza Ghanei Gheshlagh ${ }^{2}$
}

\begin{abstract}
Background: Smartphone addiction is one of the most important forms of technology addiction that has attracted the attention of all countries around the world. Many studies have been conducted in Iran on cellphone addiction among different groups. There is a necessity to have a native scale for measuring smartphone addiction in particular. Therefore, this study aimed to localize the smartphone addiction questionnaire in Iran (in the Persian language).

Methods: To assess the validity and reliability of the Persian version of the smartphone addiction scale (SAS), the questionnaire was first provided based on the standard back-translation method. Next, content validity ratio (CVR), content validity index (CVI), and face validity was evaluated for translated questionnaire. After making the necessary changes, the questionnaire was given to the community samples and was then reviewed using confirmatory factor analysis of questions grouping. Finally, the reliability of the questionnaire was investigated by the test-retest method.

Results: The CVR and CVI values of all questions were within the acceptable range. Only some of the questions in the original SAS version titled Twitter and Facebook were changed to Instagram and telegram according to experts. Internal consistency and concurrent validity of the questionnaire were confirmed by Cronbach's alpha of 0.951. The mean correlation coefficient between the responses of the subjects, who received the questionnaire twice, was 0.946 (0.938-0.954). The grouping of questions in the subscales was changed from the original SAS version because the fitting indexes, obtained from the confirmatory factor analysis test (for example CMIN/DF greater than 5 units and RMSEA of approximately 0.07), were not acceptable.
\end{abstract}

Conclusion: The results showed that the Iranian version of the cellphone addiction questionnaire can be used as a valid, with minimal modification, tool for determining the level of smartphone addiction among Persian speakers.

Keywords: Validity, Reliability, SAS questionnaire, Smartphone addiction, Confirmatory factor analysis

\footnotetext{
* Correspondence: aqaei.a@gmail.com

${ }^{2}$ Social Determinants of Health Research Center, Research Institute for Health Development, Kurdistan University of Medical Sciences, Sanandaj, Iran

Full list of author information is available at the end of the article
}

(c) The Author(s). 2021 Open Access This article is licensed under a Creative Commons Attribution 4.0 International License, which permits use, sharing, adaptation, distribution and reproduction in any medium or format, as long as you give appropriate credit to the original author(s) and the source, provide a link to the Creative Commons licence, and indicate if changes were made. The images or other third party material in this article are included in the article's Creative Commons licence, unless indicated otherwise in a credit line to the material. If material is not included in the article's Creative Commons licence and your intended use is not permitted by statutory regulation or exceeds the permitted use, you will need to obtain permission directly from the copyright holder. To view a copy of this licence, visit http://creativecommons.org/licenses/by/4.0/ The Creative Commons Public Domain Dedication waiver (http://creativecommons.org/publicdomain/zero/1.0/) applies to the data made available in this article, unless otherwise stated in a credit line to the data. 


\section{Background}

Technology and the growth of industry certainly affect human health. Today, there is a significant increase in the excessive use of cellphones [1]. Smartphones are not only cellphones anymore, but also a means of accessing many of the latest technologies including the Internet at any time and place. Therefore, with this capability, many people seek to develop and use it [2,3]. In such a situation, smartphone addiction can be considered as the most important form of technology addiction that has attracted the attention of countries around the world [4-7]. Studies by the Korea National Intelligence Association in 2012 showed that smartphone addiction and internet addiction were 8.4 and $7.7 \%$, respectively [4].

In Korea, simple statistical methods were used to evaluate smartphone addiction. However due to the ambiguity and limitations of this method, Kwon et al. designed a smartphone addiction scale (SAS) for the first time and evaluated its reliability and validity in Kangwon, Korea [8]. This questionnaire was developed according to the many aspects of smartphone addiction and the K-scale (Korean self-diagnostic program for Internet addiction), derived from the Kimberly Young Internet Addiction Scale. Then, it has been revised and finalized using factor analysis [9-12]. As a result of this research, Cronbach's alpha showed $96.6 \%$ internal consistency of the items of this 33-item questionnaire [8]. The reliability and validity of this questionnaire in Turkey (2014) and Malaysia (2015) have also been evaluated by Akin Ahmed et al. and Ching et al., respectively $[13,14]$. There have been many studies of cellphone addiction in Iran across different groups [15-20], but there is no exact study due to the lack of a native scale for measuring smartphone addiction in particular. Therefore, the present study aimed to localize the SAS questionnaire among the Iranian population (Kermanshah city).

\section{Methods}

\section{Study design}

This cross-sectional methodological study was conducted to evaluate the psychometric properties of the Persian version of the Smartphone Addiction Scale.

\section{Participants}

The study samples included 360 staff and clients of two general and large hospitals of Kermanshah (Imam Khomeini Hospital and Imam Reza Hospital) who were selected by convenience sampling. Since these hospitals are referral centers in western Iran, their clients (Patients and accompanying person) cover almost every spectrum of society, so it was attempted to select generalizable samples from the hospital staff and clients.

\section{Translation}

After obtaining permission from the original designer, the English version of the Smartphone Addiction Scale was translated into Persian by two independent translators. The two translated versions were compared and a single version was compiled by the research team. The original version of the questionnaire was prepared by comparing and combining the two versions according to the agreement of the authors. Then, the items that needed to be corrected were reviewed and corrected by both translators through comparing two translated texts and providing feedback to two translators. The final translated text was given to another translator, who was fluent in English, and finally, the translated text was matched to the original English text and provided to all three translators. Finally, minor cases were corrected in coordination with all translators.

\section{Face validity}

After evaluating the content validity of the questionnaire and making the necessary corrections, the face validity of the questionnaire is accessed by 5 experts in the study subject, and 22 target groups, who were selected by easy sampling from hospital staff. They were asked to comment on the difficulty or simplicity of the questions, their meaning, or any ambiguity in the questions, phrases or words after reading and completing the questionnaire. The corrections are made in case of necessity as the necessary questions are received.

\section{Content validity}

An expert panel consisting of 15 experts in the field of study is used to assess the content validity of the questionnaires: 5 in health education and health promotion, 4 in epidemiology, 4 in psychology, and 2 in sociology. To determine the content validity ratio (CVR), the experts were asked to examine each question on a threepart range of "essential", "useful but unnecessary" and "unnecessary". Moreover, the content validity index (CVI) was separately evaluated by experts through three criteria of simplicity, appropriateness and certainty based on a four-part spectrum (for example, in terms of simplicity, quite simple, somewhat complex and complex) for each question and the corresponding ratings were given. Finally, the content validity indices were measured and judged by each question, each subscale and the whole questionnaire.

\section{Data analysis}

Exploratory factor analysis was used to evaluate the construct validity. Adequacy of sampling was assessed by Kaiser-Meyer-Olkin (KMO) and Bartlett test. Extraction of latent agents was performed using the Maximum Likelihood method and Varimax rotation by SPSS 
Table 1 Results of the content validity indexes for the SAS questionnaire

\begin{tabular}{|c|c|c|c|c|c|}
\hline Subscale & Question & CVR & $\begin{array}{l}\text { Simplicity } \\
\text { CVI }\end{array}$ & $\begin{array}{l}\text { Appropriateness } \\
\mathrm{CVI}\end{array}$ & $\begin{array}{l}\text { certainty } \\
\text { CVI }\end{array}$ \\
\hline \multirow{5}{*}{$\begin{array}{l}\text { Daily life disturbance } \\
\text { (q1-q5) }\end{array}$} & Missing planned work due to smartphone use & 1 & 1 & 1 & 1 \\
\hline & $\begin{array}{l}\text { Having a hard time concentrating in class, while doing assignments, } \\
\text { or while working due to smartphone use }\end{array}$ & 0.8 & 0.8 & 0.8 & 0.8 \\
\hline & $\begin{array}{l}\text { Experiencing lightheadedness or blurred vision due to excessive } \\
\text { smartphone use }\end{array}$ & 0.8 & 1 & 1 & 1 \\
\hline & $\begin{array}{l}\text { Feeling pain in the wrists or at the back of the neck while using a } \\
\text { smartphone }\end{array}$ & 1 & 1 & 1 & 1 \\
\hline & $\begin{array}{l}\text { Feeling tired and lacking adequate sleep due to excessive } \\
\text { smartphone use }\end{array}$ & 1 & 1 & 1 & 1 \\
\hline \multirow{8}{*}{$\begin{array}{l}\text { Positive anticipation } \\
\text { (q6-q13) }\end{array}$} & Feeling calm or cozy while using a smartphone & 0.8 & 1 & 1 & 1 \\
\hline & Feeling pleasant or excited while using a smartphone & 0.8 & 1 & 1 & 1 \\
\hline & Feeling confident while using a smartphone & 0.8 & 1 & 0.6 & 1 \\
\hline & Being able to get rid of stress with a smartphone & 0.8 & 1 & 0.8 & 1 \\
\hline & There is nothing more fun to do than using my smartphone. & 0.8 & 1 & 1 & 1 \\
\hline & My life would be empty without my smartphone. & 0.8 & 1 & 1 & 1 \\
\hline & Feeling most liberal while using a smartphone & 0.6 & 0.8 & 1 & 1 \\
\hline & Using a smartphone is the most fun thing to do. & 1 & 1 & 1 & 1 \\
\hline \multirow[t]{6}{*}{ Withdrawal (q14-q19) } & Won't be able to stand not having a smartphone & 0.8 & 1 & 0.8 & 1 \\
\hline & Feeling impatient and fretful when I am not holding my smartphone & 0.8 & 1 & 1 & 1 \\
\hline & Having my smartphone in my mind even when I am not using it & 0.8 & 0.8 & 0.8 & 1 \\
\hline & $\begin{array}{l}\text { I will never give up using my smartphone even when my daily life is } \\
\text { already greatly affected by it. }\end{array}$ & 1 & 0.8 & 1 & 0.8 \\
\hline & Getting irritated when bothered while using my smartphone & 0.6 & 1 & 0.8 & 1 \\
\hline & $\begin{array}{l}\text { Bringing my smartphone to the toilet even when I am in a hurry to } \\
\text { get there }\end{array}$ & 0.8 & 0.8 & 0.8 & 1 \\
\hline \multirow{7}{*}{$\begin{array}{l}\text { Cyberspace oriented } \\
\text { relationship (q20-q26) }\end{array}$} & Feeling great meeting more people via smartphone use & 0.6 & 0.8 & 0.8 & 1 \\
\hline & $\begin{array}{l}\text { Feeling that my relationships with my smartphone buddies are more } \\
\text { intimate than my relationships with my real-life friends }\end{array}$ & 0.6 & 0.8 & 0.8 & 1 \\
\hline & $\begin{array}{l}\text { Not being able to use my smartphone would be as painful as losing a } \\
\text { friend. }\end{array}$ & 0.8 & 1 & 1 & 1 \\
\hline & $\begin{array}{l}\text { Feeling that my smartphone buddies understand me better than my } \\
\text { real-life friends }\end{array}$ & 0.8 & 1 & 0.8 & 1 \\
\hline & $\begin{array}{l}\text { Constantly checking my smartphone so as not to miss conversations } \\
\text { between other people on Telegram or Instagram }\end{array}$ & 1 & 1 & 1 & 1 \\
\hline & $\begin{array}{l}\text { Checking SNS (Social Networking Service) sites like Telegram or } \\
\text { Instagram right after waking up }\end{array}$ & 1 & 1 & 1 & 1 \\
\hline & $\begin{array}{l}\text { Preferring talking with my smartphone buddies to hanging out with } \\
\text { my real-life friends or with the other members of my family }\end{array}$ & 1 & 0.8 & 1 & 1 \\
\hline \multirow[t]{4}{*}{ Overuse (q27-q30) } & Preferring searching from my smartphone to asking other people & 0.8 & 1 & 0.8 & 1 \\
\hline & My fully charged battery does not last for one whole day. & 0.8 & 1 & 1 & 1 \\
\hline & Using my smartphone longer than I had intended & 0.8 & 0.8 & 0.8 & 1 \\
\hline & $\begin{array}{l}\text { Feeling the urge to use my smartphone again right after I stopped } \\
\text { using it }\end{array}$ & 1 & 1 & 0.8 & 1 \\
\hline \multirow[t]{3}{*}{ Tolerance (q31-q33) } & $\begin{array}{l}\text { Having tried time and again to shorten my smartphone use time, but } \\
\text { failing all the time }\end{array}$ & 1 & 1 & 1 & 1 \\
\hline & Always thinking that I should shorten my smartphone use time & 1 & 1 & 1 & 1 \\
\hline & The people around me tell me that I use my smartphone too much. & 1 & 1 & 1 & 1 \\
\hline
\end{tabular}


Table 2 Factors identified in exploratory factor analysis of the localized version of the SAS questionnaire

\begin{tabular}{lllll}
\hline Factors & Eigenvalue & \multicolumn{3}{c}{ Rotation Sums of Squared Loadings } \\
\cline { 3 - 5 } & & Total & \% of Variance & Cumulative\% \\
\hline 1 & 12.99 & 4.74 & 14.37 & 14.37 \\
2 & 2.08 & 3.85 & 11.67 & 26.04 \\
3 & 2.03 & 3.64 & 11.03 & 37.08 \\
4 & 1.57 & 3.23 & 9.79 & 46.86 \\
5 & 1.25 & 2.86 & 8.68 & 55.54 \\
6 & 0.95 & 2,55 & 7.73 & 63.27 \\
\hline
\end{tabular}

software version 25. The cut-off point of factor loading was considered to be 0.30. 360 new available samples were selected for confirmatory factor analysis (CFA). At this stage, fit indicators such as the goodness of fit index (GFI), chi-square test $(x 2)$, degrees of freedom (df), root mean square error of approximation (RMSEA), confirmatory fit index (CFI), standardized root mean square residuals (SRMR), and Tucker-Lewis index (TLI) fit indices were evaluated. Internal consistency with Cronbach's alpha coefficient and instrument stability was calculated by the interclass correlation (ICC) with a Two-way mixed-effects model and absolute agreement with a 95\% confidence interval.

\section{Results}

\section{Participants' characteristics}

The samples included 175 females and 185 males with a mean age of 32.19328 .53 years. Of these, 74 were hospital staff, 56 were patients, 188 were patient's accompanies and 42 were students. In terms of education, 29 people had primary and secondary education, 96 people had high school education and the rest had university education.

\section{Validity}

The content validity of the questionnaire is evaluated by 11 experts from the panel (consist of $2 \mathrm{PhDs}$ in Epidemiology, $3 \mathrm{PhDs}$ in Health Education, $2 \mathrm{PhDs}$ in Sociology, 1 MSc in Health Education, 1 Ph.D. in Health Policy, 1 Ph.D. in Health Care Management, 1 MSc in psychology). To determine the content validity ratio (CVR), the experts were asked to examine each question on a three-part range of "essential", "useful but unnecessary" and "unnecessary". Moreover, the content validity index (CVI) was separately evaluated by experts through three criteria of simplicity, appropriateness and certainty based on a four-part spectrum (for example, in terms of simplicity, quite simple, somewhat complex and complex) for each question and the corresponding ratings were given. Finally, the content validity indices were measured and judged by each question, each subscale and the whole questionnaire. The CVR values of all questions varied between $0.6-1$ concerning the 11 experts in this study and it was above the established recommended levels (minimum validity was 0.59) [21], then all questions were considered essential and none were eliminated. The CVI value for all questions varied between $0.8-1$, which is in the acceptable range. The scores of simplicity, appropriateness and certainty for all questions were $0.94,0.91$, and 0.98 , respectively. However, some questions were changed according to the opinion of expert panel members. For example, Telegram and Instagram are used in this study instead of the original version for social networks such as Twitter and Facebook (Table 1).

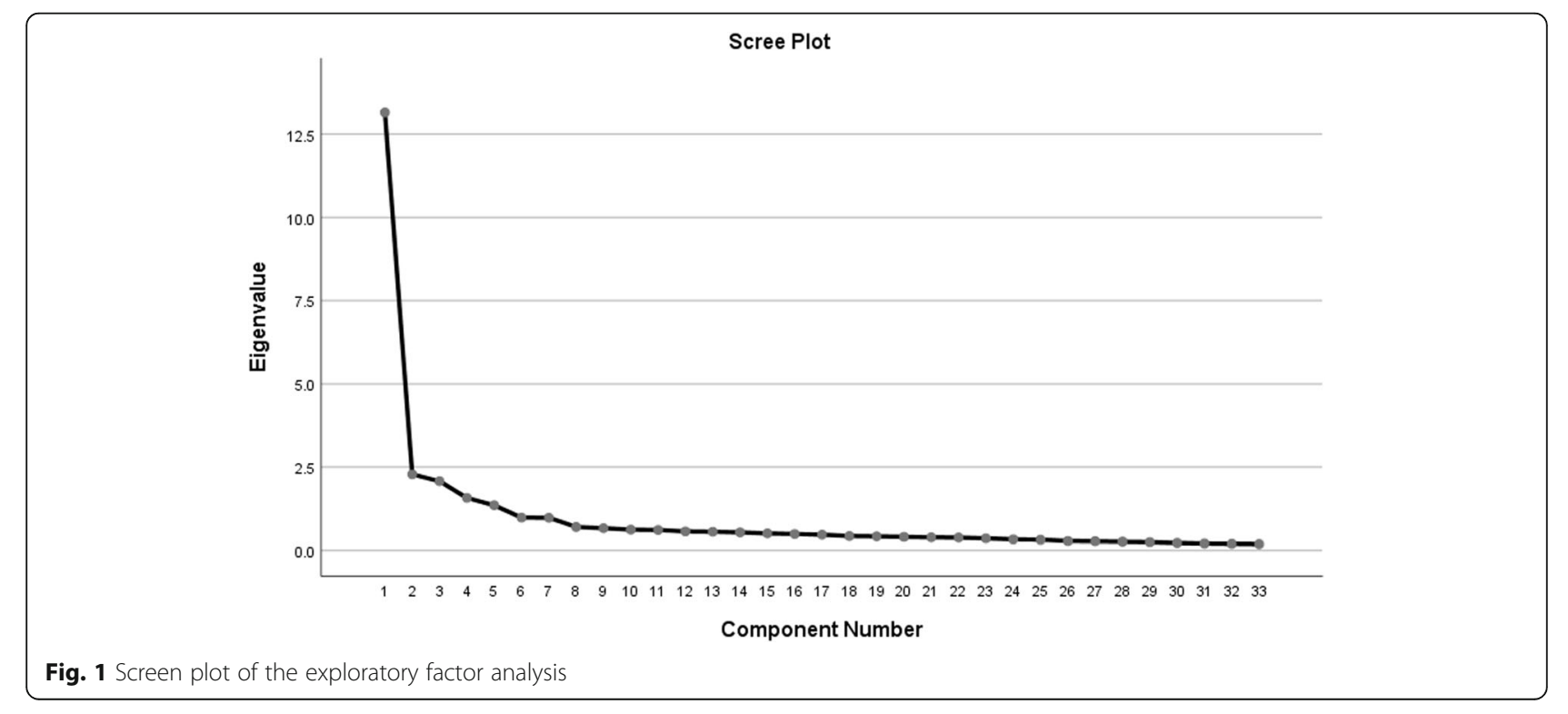


Table 3 Grouping of question s in Persian version of SAS questionnaire based on exploratory factor analysis

\begin{tabular}{|c|c|c|c|c|c|c|}
\hline \multicolumn{7}{|c|}{ Rotated Component Matrix ${ }^{\mathrm{a}}$} \\
\hline & \multicolumn{6}{|l|}{ Component } \\
\hline & Daily life disturbance & Positive Anticipation & Withdrawal & Cyberspace oriented relationship & Overuse & Tolerance \\
\hline Q1 & 0.625 & & & & & \\
\hline Q2 & 0.714 & & & & & \\
\hline Q3 & 0.797 & & & & & \\
\hline Q4 & 0.727 & & & & & \\
\hline Q5 & 0.718 & & & & & \\
\hline Q6 & & 0.766 & & & & \\
\hline Q7 & & 0.747 & & & & \\
\hline Q8 & & 0.779 & & & & \\
\hline Q9 & & 0.729 & & & & \\
\hline Q10 & & & 0.505 & & & \\
\hline Q11 & & & 0.649 & & & \\
\hline Q12 & & & 0.475 & & & \\
\hline Q13 & & & 0.638 & & & \\
\hline Q14 & & & 0.659 & & & \\
\hline Q15 & & & 0.746 & & & \\
\hline Q16 & & & 0.686 & & & \\
\hline Q17 & & & 0.629 & & & \\
\hline Q18 & & & 0.573 & & & \\
\hline Q19 & & & 0.306 & & & \\
\hline Q20 & & & & 0.674 & & \\
\hline Q21 & & & & 0.713 & & \\
\hline Q22 & & & & 0.501 & & \\
\hline Q23 & & & & 0.733 & & \\
\hline Q24 & & & & 0.550 & & \\
\hline Q25 & & & & & 0.660 & \\
\hline Q26 & & & & & 0.364 & \\
\hline Q27 & & & & & 0.773 & \\
\hline Q28 & & & & & 0.521 & \\
\hline Q29 & & & & & & 0.511 \\
\hline Q30 & & & & & & 0.540 \\
\hline Q31 & & & & & & 0.683 \\
\hline Q32 & & & & & & 0.777 \\
\hline Q33 & & & & & & 0.613 \\
\hline
\end{tabular}

Extraction Method: Principal Component Analysis

Rotation Method: Varimax with Kaiser Normalization

a Rotation converged in 7 iterations

In exploratory factor analysis, the $\mathrm{KMO}$ criterion was 0.957 and the Bartlett sphericity test was significant $(\mathrm{X} 2=15,748.6, \mathrm{p}=<0.001)$.

In the exploratory factor analysis, 6 factors were extracted that were able to explain $63.267 \%$ of the total variance (Table 2).
Fig. 1 shows the screen plot of the exploratory factor analysis applied in this study. Also the grouping of questions in the Persian version of SAS questionnaire based on exploratory factor analysis is reported in Table 3.

Confirmatory factor analysis was performed based on the new category, because many of the indexes of 


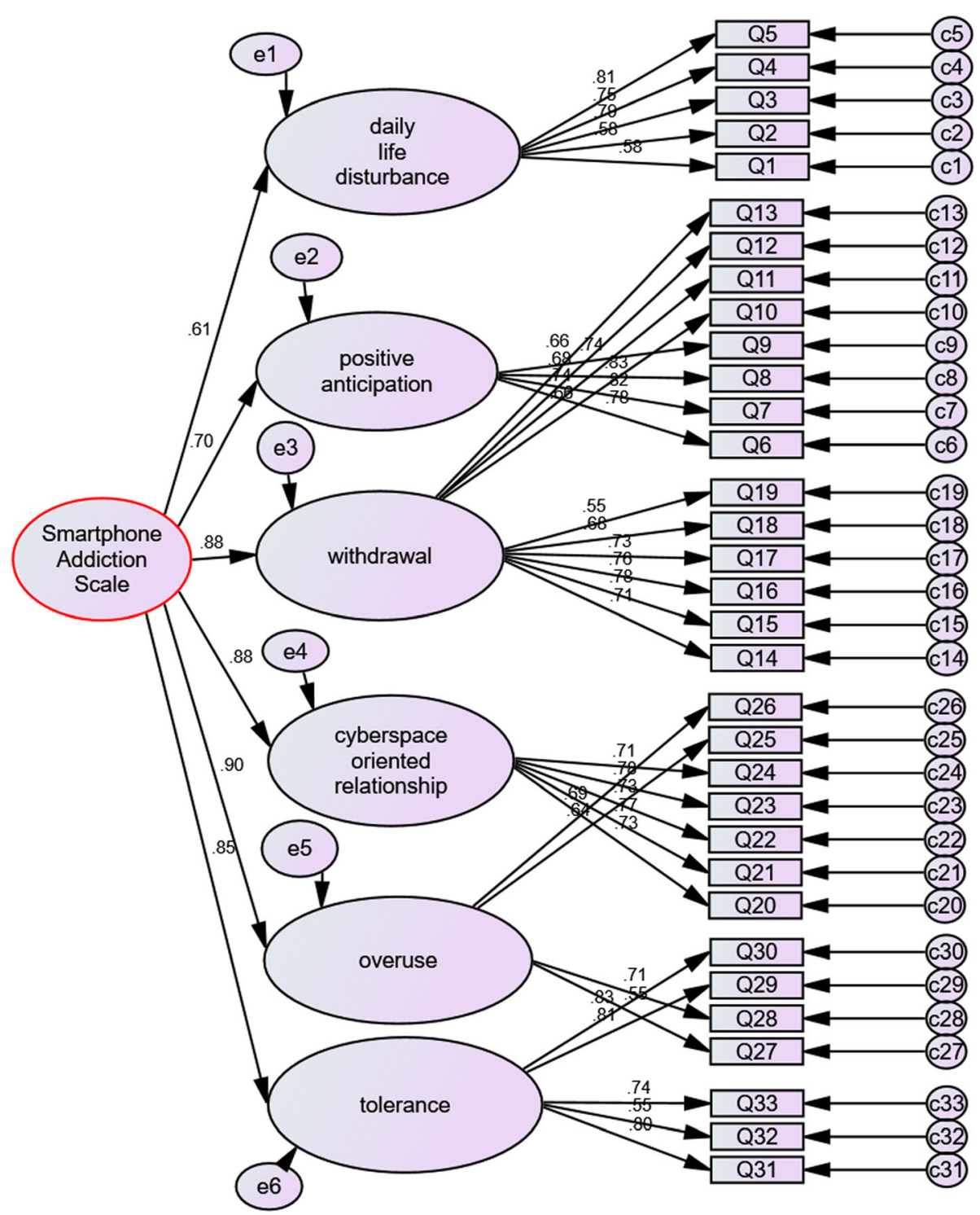

Fig. 2 The final model. This model is the output of Amos software based on confirmatory factor analysis was performed on the results of the SAS Persian version. Arrows that fall out of their respective categories and are drawn to another category, the differences found between the original version of SAS and its Persian version are based on the confirmatory analysis factor

confirmatory factor analysis fitting based on initial classification (according to the original study of SAS) were not appropriate, for example, the $\mathrm{Chi}^{2}$ likelihood ratio statistic (CMIN/DF) was larger than 5 units and RMSEA was approximately equal to 0.07 . In the next step, confirmatory factor analysis was performed based on the results of the Persian version of the factor analysis. Figure 2 depicts the output of Amos software based on exploratory factor analysis for this analysis for the Persian version of SAS questionnaire.

Comparison of the general indices of the results of the confirmatory factor analysis based on the results of the

Table 4 General fitting indexes of the confirmatory factor analysis model based on the results of the new classification of Persian SAS questionnaire

\begin{tabular}{lllllllllll}
\hline RMSEA & PCFI & PNFI & CMIN/DF & TLI & CFI & RFI & IFI & P & DF & CMIN \\
\hline 0.058 & 0.837 & 0.812 & 3.882 & 0.901 & 0.909 & 0.872 & 0.910 & $<0.001$ & 489 & 1898.298
\end{tabular}

RMSEA: root mean square error of approximation, PCFI: parsimony comparative fit index, PNFI: Parsi-mony normed fit index, CMIN/DF: the Chi ${ }^{2}$ likelihood ratio statistic, TLI: Tucker-Lewis index, CFI: comparative fit index, RFI: relative fit index, IFI: incremental fit index, P: $p$-value, DF: degree of freedom, CMIN: 
Table 5 Final grouping of questions in subscales for Persian version of SAS questionnaire

\begin{tabular}{lll}
\hline Subscale & Questions based on Persian version of SAS & Questions based on original SAS \\
\hline Daily life disturbance & Question 1-5 & Question 1-5 \\
Positive anticipation & Question 6-9 & Question 6-13 \\
Withdrawal & Question 10-19 & Question 14-19 \\
Cyberspace oriented relationship & Question 20-24 & Question 20-26 \\
Overuse & Question 25-28 & Question 27-30 \\
Tolerance & Question 29-33 & Question 31-33 \\
\hline
\end{tabular}

new classification of the localized SAS questionnaire with the general fitting indexes of the factor analysis model based on the initial classification showed that all indexes are improved. For example, the CMIN/DF and RMSEA indices were lower than 4 and 0.06 , respectively (Fig. 2 and Table 4).

The Chi-square index (CMIN) has been decreased based on the results of the new classification of the localized SAS questionnaire, and other indices have been increased. The reliability calculated using Cronbach's alpha coefficient was 0.951 . The mean correlation coefficient between the responses of the subjects who received the questionnaire twice was $0.946(0.938-0.954)$. Finally, the grouping of questions for the Persian version of SAS questionnaire is obtained based on this study as shown in Table 5.

\section{Discussion}

The purpose of this study was to localize the SAS questionnaire. The CVR and CVI values of all questions were within the acceptable range and none of the questions were eliminated. It should be mentioned that some of the questions in the original SAS version titled Twitter and Facebook were changed to Instagram and Telegram according to the authors. Internal consistency and concurrent validity of the questionnaire were confirmed with Cronbach's alpha of 0.951 . These values were reported for other previous studies as follows: Min Kwon et al. [8] (Original version of SAS questionnaire) obtained internal consistency and reliability of the questionnaire with Cronbach's alpha of 0.967. Ching et al. [14] investigated the validity and reliability of the SAS questionnaire in Malaysia with Cronbach's alpha of 0.94. The Cronbach's alpha for validity and reliability of the shortened SAS version conducted by Bede C. Akpunne et al. [22] in Nigeria was 0.82 . Khalily et al. [23] investigated the validity and reliability of the short version of SAS in Pakistan (Urdu language) with Cronbach's alpha coefficient of 0.81 which was consistent with the original SAS version.

The value of Cronbach's alpha in the present study is much closer to that of the original study. This can be explained by the fact that the target group in our study (employees, 20-60 years) was closer to the original study (in the original study, $18-53$ years). The mean age of Ching et al.'s study [14] was 21 years for high school students. The age range of the participants in the study of Khalily et al. [23] was $18-20$ years.

The grouping of questions in the subscales was changed from the original SAS version because the fitting indexes, obtained from the confirmatory factor analysis test, were not appropriate validating factors (e.g. CMIN/ DF greater than 5 units and RMSEA of approximately 0.07). Therefore, exploratory factor analysis was applied and confirmatory factor analysis was utilized based on this analysis. The results showed that the values of the fitting indices were improved (CMIN/DF and RMSEA indices were less than 4 and 0.06 , respectively) and changes were made to the question grouping, but none of the subscales and questions were deleted.

These changes were such that no changes were made to the "daily life disturbance" factor and constructs included questions number 1 to 5 in the original version. However, the changes of question numbers for other factors were as follows: "positive anticipation" included question numbers 6 to 9 while it was from question number 6 to 13 in the original version; "withdrawal" included question numbers 10 to 19 while it was from question number 14 to 19 in the original version; "cyberspace oriented relationship" included question numbers 20 to 24 while it was from question number 20 to 26 in the original version; "overuse" included question numbers 25 to 28 while it was from question number 27 to 30 in the original version, and "tolerance" included question numbers 29 to 33 while it was from question number 31 to 33 in the original version.

In the study conducted by Ching et al. [14], the validity and reliability of the SAS questionnaire are assessed by the Malaysian language and evaluated the questionnaire with correlation analysis, factor analysis and t-test. They concluded that the internal consistency and reliability of the questionnaire are confirmed by Alpha Cronbach of 0.94 . They also showed that all constructs except positive anticipation constructs were related to the original version and the questionnaire was applicable by omitting the positive anticipation factor.

At first glance, the use of hospital population may be considered as a weakness in this study, but since the 
hospitals are two large and public hospitals in Kermanshah metropolis and the sampling among the hospital staff, patients and their companions as well as students, were taken, it can be said that the samples can be somewhat similar to the general population.

\section{Conclusion}

Although there were slight changes in the Persian version of SAS questionnaire from the original questionnaire (which requires localization in a different culture), the results showed that the validity and reliability of the Persian version of SAS questionnaire were acceptable. These minor changes did not make much difference to the original SAS questionnaire questions.

\section{Abbreviations}

CFA: confirmatory factor analysis; CFI: comparative fit index; CMIN: Chi-square index; CMIN/DF: the $\mathrm{Chi}^{2}$ likelihood ratio statistic; CVR: content validity ratio; CVI: content validity index; DF: degree of freedom; GFI: goodness-of-fit index; IFI: incremental fit index; NFI: normed Fit Index; PCFl: parsimony comparative fit index; PNFI: Parsi-mony normed fit index; RFI: relative fit index;

RMSEA: root mean square error of approximation; SAS: smartphone addiction scale; SRMR: standardized root mean squared error; TLI: Tucker-Lewis index

\section{Acknowledgments}

The authors would like to thank the experts of Imam Khomeini and Dr. Mohammad Kermanshahi Clinical Research Development Center, those who supported us in collecting data and those who cooperated to complete the research questionnaires.

\section{Authors' contributions}

All authors contributed to the study conception and design. Concept design: ZS, data collection; data analysis: AA. All authors read, commented on, and approved the final manuscript.

\section{Funding}

This research funded by Kermanshah University of Medical Sciences (grant number: 95652).

\section{Availability of data and materials}

The datasets generated and/or analysed during the current study are not publicly available because the intellectual property is owned by the funding body. They may be available from the corresponding author on reasonable request subject to approval from the funding body.

\section{Declarations}

\section{Ethics approval and consent to participate}

Approval was obtained from Kermanshah University Research Ethics Committee (IR.KUMS.REC.1395.462). The procedures used in this study adhere to the tenets of the Declaration of Helsinki. Informed consent was obtained from all individual participants included in the study.

\section{Consent for publication}

Not applicable.

\section{Competing interests}

The authors declare that they have no competing interests.

\section{Author details}

${ }^{1}$ Clinical Research Development Center, Imam Khomeini and Mohammad Kermanshahi and Farabi Hospitals, Kermanshah University of Medical Sciences, Kermanshah, Iran. ${ }^{2}$ Social Determinants of Health Research Center, Research Institute for Health Development, Kurdistan University of Medical Sciences, Sanandaj, Iran.
Accepted: 8 September 2021

Published online: 17 September 2021

\section{References}

1. Brennecke JF, Gurkan BE. Ionic liquids for CO2 capture and emission reduction. J Physical Chem Letters. 2010;1(24):3459-64.

2. Kuss DJ, Griffiths MD. Online social networking and addiction-a review of the psychological literature. Int J Environ Res Public Health. 2011;8(9):352852.

3. Park N, Lee H. Social implications of smartphone use: Korean college students' smartphone use and psychological well-being. Cyberpsychol Behav Soc Netw. 2012;15(9):491-7.

4. Internet Addiction Survey 2011, in National Information Society Agency Seoul: National Information Society Agency, 2012:118-119.

5. Bahri N, SadeghMoghadam L, Khodadost L, Mohammadzade J, Banafsheh E. Internet addiction status and its relation with students' general health at Gonabad Medical University. Modern Care 2011; 8 (3). http://sid.bums.ac.ir/ dspace/handle/bums/5250.

6. Kamibeppu K, Sugiura H. Impact of the mobile phone on junior high-school students' friendships in the Tokyo metropolitan area. Cyberpsychol Behavior 2005:8(2):121-30.

7. Takao M, Takahashi S, Kitamura M. Addictive personality and problematic mobile phone use. CyberPsychol Behavior. 2009;12(5):501-7.

8. Kwon M, Kim DJ, Cho H, Yang S. The smartphone addiction scale: development and validation of a short version for adolescents. PLoS One. 2013;8(12):e83558.

9. Chang MK, Law SPM. Factor structure for Young's internet addiction test: a confirmatory study. Comput Hum Behav. 2008;24(6):2597-619.

10. Kim C, Kim D, Park J, Lee S. A study on internet addiction counseling and the development of prevention programs. Seoul: National IT Industrial Promotion Agency; 2002.

11. Kim D, Chung Y, Lee E, Kim D, Cho Y. Development of internet addiction proneness scale-short form (KS scale). Korea J Counseling. 2008;9(4):1703 $-1722,2008$.

12. Young KS. Internet addiction: the emergence of a new clinical disorder. Cyberpsychol Behavior. 1998;3(1):237-44.

13. Akın A, Altundağ $Y$, Turan ME, Akın U. The validity and reliability of the turkish version of the smart phone addiction scale-short form for adolescent. Procedia Soc Behav Sci. 2014;152:74-7.

14. Ching SM. Validation of a Malay version of the smartphone addiction scale among medical students in Malaysia. PLoS One. 2015;10(10):e0139337.

15. Babadi-Akashe Z, Zamani BE, Abedini Y, Akbari H, Hedayati N. The relationship between mental health and addiction to Mobile phones among university students of Shahrekord, Iran. Addiction Health. 2014;6(3): 93-9.

16. Golmahammadian M, Yyaseminejad P. Normalization, validity and reliability of cell-phone over-use scale (COS) among university students. J Social Phychol. 2011;19(6):37-52.

17. Khazaie T, Saadatjoo A, Dormohamadi S, Soleimani M, Toosinia M. Mullah Hassan Zadeh F. prevalence of mobile dependency and adolescence aggression. J Birjand University Med Sci. 2012;19(4):430-8.

18. Mansourian M, Solhi M, Adab Z, Latifi M. Relationship between dependence to mobile phone with loneliness and social support in university students. Razi J Med Sci. 2014;21:1-8.

19. Mortazavi SMJ, Atefi M, Kholghi F. The pattern of mobile phone use and prevalence of self-reported symptoms in elementary and junior high school students in shiraz, Iran. Iran J Med Sci. 2011;36(2):96-103.

20. Shahbazi $\mathrm{H}$. The impact of Mobile phone on social and educational performance of students in Yazd in 2012. Global Media J Persian. 2012;8(2): 69-89.

21. Lawshe CH. A quantitative approach to content validity. Pers Psychol. 1975; 28(4):563-75.

22. Akpunne BC, Akinnawo OE. Validation of smartphone addiction scale-short version on nigerian university undergraduates; 2018.

23. Khalily MT, Saleem T, Bhatti MM, Ahmad I, Hussain B. An Urdu adaptation of smartphone addiction scale-short version (SAS-SV), JPMA. J Pakistan Med Assoc. 2019;69(5):700-10

\section{Publisher's Note}

Springer Nature remains neutral with regard to jurisdictional claims in published maps and institutional affiliations. 